\title{
The Rapid Growth of Permanent Mail Ballot Registration in California and its Impact
}

Mark DiCamillo*

Tags: survey practice

\section{Survey Practice}

Vol. 2, Issue 7, 2009

The Rapid Growth of Permanent Mail Ballot Registration in California and its Impact

The growth of mail ballot voting in California has been a long-term trend that began in the late 1970's after restrictions to this voting method were lifted allowing any voter the right to vote in this manner. However, the number of Californians choosing to vote by mail has been increasing at an accelerated rate in recent years. According to official estimates from the California Secretary of State, "vote-by-mail" voters included slightly more than 5.7 million Californians in the 2008 presidential election, up 1.6 million from the previous state record of 4.1 million in 2004, and more than double the 2.7 million who cast a mail ballot in the 2000 presidential election. $[\wedge 1]$

One of the reasons behind the recent expansion in mail ballot voting is a further change in state election law enacted in 2001 which enables all registered voters to permanently receive their ballots by mail without having to request them for each individual election. In the relatively short period since then, the popularity of the state's permanent mail ballot registry has skyrocketed, increasing from just 279,000 in the 2000 presidential election to 5,565,105 in the 2008 presidential election.

During the 1976-2000 period, which spans the time from when mail ballot voting first became widely available to the introduction of the permanent mail ballot registry, there was a steady increase in the number of Californians voting by mail in each presidential election. The data in Table 2 documents this growth, as the number of vote-by-mail voters increased from 367 thousand in 1976 to over 2.7 million in 2000 . However, the trend line atop Table 2 shows that even as the popularity of mail ballot voting was increasing over this period, voter turnout in presidential elections was generally declining. 


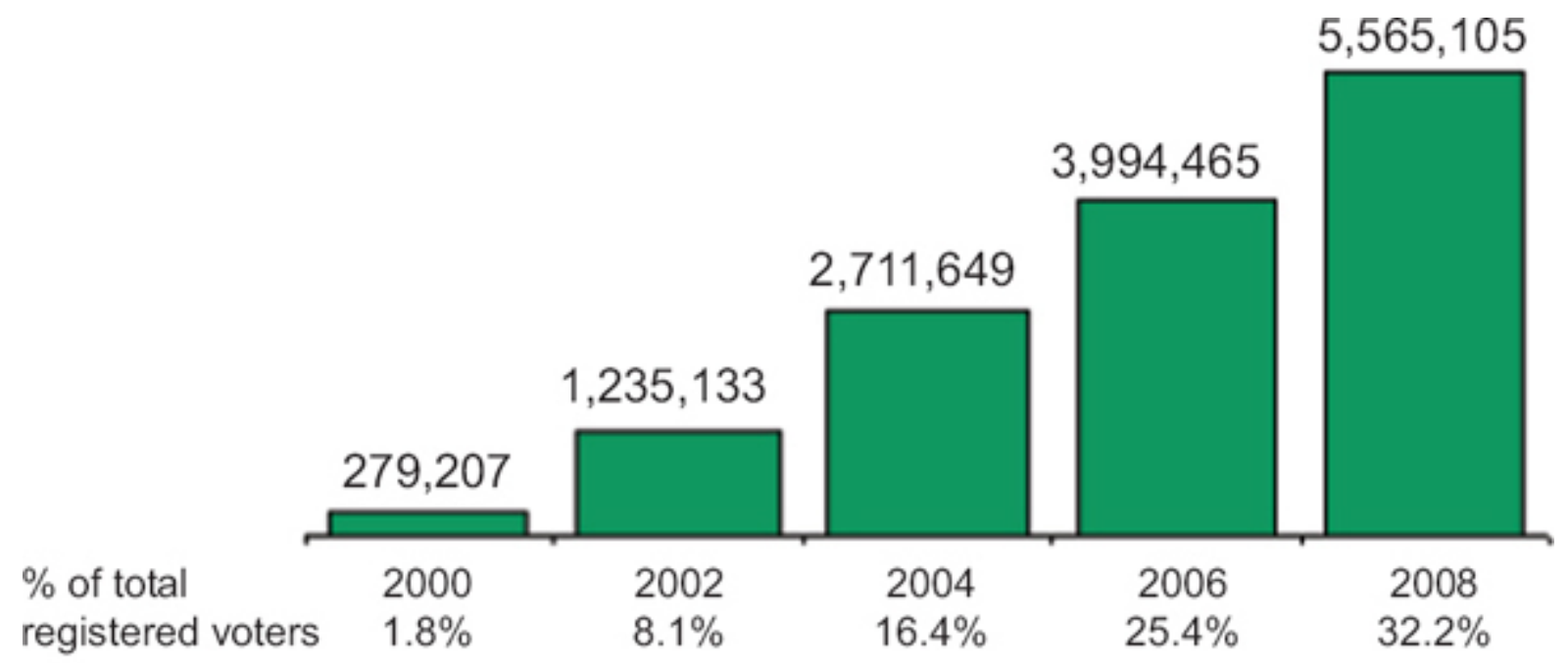

Source: California of State, California of Cleris and Election Officials.

Figure 1 Growth in permanent mail ballot registration status of California voters (2000-2008).

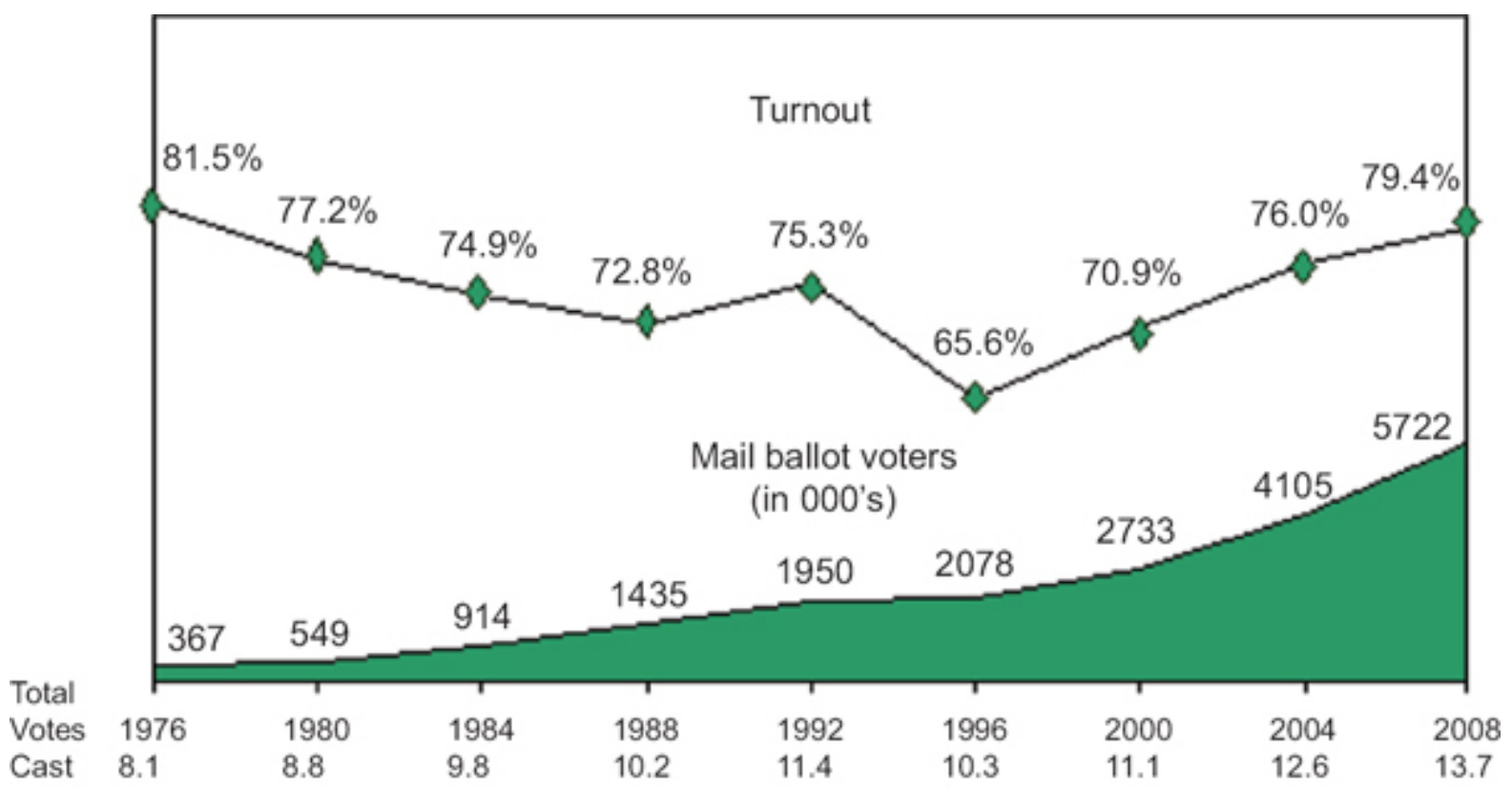

(in millions)

Source: California Secretary of State, Statements of Vote.

Figure 2 Comparing voter turnout in California presidential elections to the officialitallies of mail ballot votes cast (1976-2008).

Table 2 also shows that during the subsequent eight-year period since the permanent mail ballot registry became available, the number of vote-by-mail voters has increased more than two-fold. At the same time overall turnout in the state's last two presidential elections increased - from $70.9 \%$ in 2000 to $76.0 \%$ in 2004 and $79.4 \%$ in 2008 .

Since 2006 the California Association of County Clerks and Election Officials 
(CACCEO) has been keeping running tallies of the total number of voters who are sent a mail ballot in advance of each election. This makes it possible to compare the turnout rates of the state's vote-by-mail voters to that of the overall electorate. In the two statewide general elections in which these tallies have been available, the turnout rates of vote-by-mail voters have exceeded the state's overall turnout by significant margins. For example, in the 2006 gubernatorial election in which $56.2 \%$ of the state's registered voters participated, the turnout rate of vote-by-mail voters was $77.7 \%$. In the 2008 presidential election, when overall voter turnout reached $79.4 \%$, turnout among vote-by-mail voters was even higher, $86.3 \%$.

The CACCEO data also provide documentation that the vast majority of registered voters who were sent a mail ballot in advance of the election (greater than $80 \%$ in each election) were permanent mail ballot registrants. Thus, it is the segment of voters who were permanent mail ballot registrants who were primarily responsible for these consistently higher turnout rates.

\section{DEMOGRAPHIC DIFFERENCES BETWEEN PERMANENT MAIL BALLOT REGISTRANTS AND OTHER REGISTERED VOTERS}

According to official state registration estimates and statistics compiled by The Field Poll from its pre-election surveys of the California electorate, there are significant demographic differences between the state's permanent mail ballot registrants and other registered voters. In the 2008 presidential election these differences included the following:

- Nearly three in ten state permanent mail ballot registrants (29\%) lived in the nine-county San Francisco Bay Area, while just 10\% resided in Los Angeles County. This differed markedly from the distribution of other registered voters, $17 \%$ of whom lived in the Bay Area and 32\% in Los Angeles County.

- Permanent mail ballot registrants as a group were significantly older than other registered voters. According to The Field Poll, $58 \%$ of the state's permanent mail ballot registrants in 2008 were age fifty or older, while among other registrants the reverse was true, with 58\% under age fifty.

- Among permanent mail ballot registrants, $56 \%$ were women and $44 \%$ were men, slightly greater than the $52 \%$ to $48 \%$ advantage women held over men among other registered voters.

- Permanent mail ballot registrants included a larger proportion of white non-Hispanic voters (74\%) than other voters (61\%). Fewer permanent mail ballot voters (14\%) than other registered voters (24\%) were Latino.

- There were also partisan differences between permanent mail ballot registrants and those who were not. Among the former, $42 \%$ were 
registered Democrats, 38\% were registered Republicans and 20\% were registered as non-partisans or with a minor party. Among all other registrants, 44\% were Democrats, 29\% Republicans and 27\% were registered as non-partisans or with a minor party.

\section{MAY 2009 SPECIAL ELECTION}

In May 2009 California held another statewide special election, its third since 2003. According to the CACCEO more than 6.2 million ballots were issued to vote-by-mail voters in advance of that election, over $90 \%$ of them to permanent mail ballot registrants. Consistent with the two previous general elections, the turnout rate of vote-by-mail voters in the May 2009 election was significantly greater than the state's overall turnout. The turnout of vote-by-mail voters in the special election was $48.6 \%$ compared to an overall turnout of $28.4 \%$.

Table 1 Comparing differences between permanent mail ballot registrants and other registered votes in California in 2008.

\begin{tabular}{|c|c|c|}
\hline & Permanent mail ballot voters & All other registered voters \\
\hline \multicolumn{3}{|l|}{ Region } \\
\hline Los Angeles County & $10 \%$ & $32 \%$ \\
\hline San Francisco Bay Area & 29 & 17 \\
\hline Central Valley & 18 & 14 \\
\hline All other & 43 & 37 \\
\hline \multicolumn{3}{|l|}{ Age } \\
\hline $18-29$ & $13 \%$ & $19 \%$ \\
\hline $30-49$ & 29 & 39 \\
\hline $50-64$ & 29 & 27 \\
\hline 65 or older & 29 & 15 \\
\hline \multicolumn{3}{|l|}{ Gender } \\
\hline Male & $44 \%$ & $48 \%$ \\
\hline Female & 56 & 52 \\
\hline \multicolumn{3}{|l|}{ Race/ethnicity } \\
\hline White non-Hispanic & $74 \%$ & $61 \%$ \\
\hline Latino & 14 & 24 \\
\hline Black/Asian/other & 12 & 15 \\
\hline \multicolumn{3}{|l|}{ Party registration } \\
\hline Democrat & $42 \%$ & $44 \%$ \\
\hline Republican & 38 & 29 \\
\hline Non-partisan/other & 20 & 27 \\
\hline \multicolumn{3}{|l|}{ Political ideology } \\
\hline Conservative & $32 \%$ & $29 \%$ \\
\hline Middle-of-the-road/other & 44 & 47 \\
\hline Liberal & 24 & 24 \\
\hline
\end{tabular}

Sources: Regional voting percentages from the California Secretary of State's Statement of Vote. All other estimates come from statewide surveys conducted by The Field Poll in 2008.

In addition, 2009 estimates of the state's registered voter population show that the number of Californians on the permanent mail ballot registry continues 
to grow and is now approaching 6 million, comprising over $35 \%$ of the state's registered voters.

\section{IMPACT ON ELECTIONS AND POLLING}

The greater use of the permanent mail ballot registry extends the "voting window" for a large segment of California's registered voters from an approximately thirteen-hour period on Election Day to a three- to four-week period in the weeks leading up to each election. This has had far-reaching effects on this state's voting processes, election campaigning and even its vote count.

- Permanent mail ballot registrants are able to reference outside information aids, such as campaign materials, press reports, endorsement recommendations and web sites, as well as conversations with other people while in the act of voting. This may make these voters more informed when making their vote choices, especially for down ballot candidate races and more obscure ballot propositions. However, it also opens up the possibility of vote coaching when voters talk to others when casting their ballots.

- The timing of campaign events and advertising during the final weeks of the election has been significantly altered. Many campaigns are now beginning to air their mass media ads and send out their direct mail pieces earlier than they formerly did to ensure that their appeals reach early vote-by-mail voters.

- Targeting the vote-by-mail voters has also become a deliberate strategy of many campaigns, as they seek to identify supporters among the permanent mail ballot registry and then make outreach efforts to get these votes "in the bank" prior to election day. A recent successful example of this was the Hillary Clinton campaign during the 2008 Democratic primary in California. The Clinton campaign's harvesting of a huge number of early vote-by-mail voters was one of the main reasons why it was able to withstand a late-developing surge in Democratic voter support for Barack Obama in the campaign's final week.

- A potential downside to early vote harvesting, at least from the voter's perspective, is that those who are persuaded to cast their ballots early are unable to change their votes in the face of late campaign-related developments or news events.

- The increasing popularity of vote-by-mail balloting has significantly reduced the number of precinct votes cast on Election Day, especially in lower turnout elections. This has led to a consolidation of voting precincts in many counties. In fact, a number of rural counties have taken this consolidation to its logical conclusion and have become mail ballot-only jurisdictions. 
- Because the signatures of mail ballot voters need to be verified before their votes are counted, in recent elections millions of vote-by-mail ballots remain uncounted the day after the election. In close races this delays the announcement of election outcomes for weeks after the election.

The growing number of vote-by-mail voters has also affected the way polls are conducted in this state. For example, late pre-election polls must now identify whether a voter has already cast their ballot before asking voter preference questions to enable these questions to be asked in the past tense for those who have already voted. In addition, the identification of early voters affects the definition of likely voters in these late polls, since there is no more likely a voter than one who has already voted.

Exit polling has also been affected. Because of the growing number of mail ballots cast, exit polls are now the byproduct of two largely independent polling efforts, one conducted through intercept interviews on election day among precinct voters and a second conducted in the campaign's final days by telephone among voters who either have already voted or who intend to vote by mail. And, since only a small fraction of the total participants in recent exit polls in California have been derived from the exit poll's telephone sample of mail ballot voters (presumably due to their higher unit costs), these interviews must be given large weights, significantly reducing the net effective sample sizes of the exit polls.

\section{QUESTIONS FOR FUTURE RESEARCH}

The growing popularity of the permanent mail ballot registry raises a number of interesting questions that can potentially be addressed through survey research. For example...

- Have California's often lengthy ballots, which can include numerous complicated ballot propositions, been a factor stimulating voters' desire to receive their voting materials weeks in advance of each election?

- Has the increasing frequency of statewide elections in California (there has now been at least one statewide election in seven of the last eight calendar years) also moved more registered voters to choose to permanently receive their ballots by mail?

- Do permanent mail ballot voters spend more time and acquire more information about the various candidate and ballot proposition election contests than other voters?

- Do permanent mail ballot registrants express any greater satisfaction voting by mail than voting at their local voting precincts on Election Day? 
- Should we expect the number of permanent mail ballot registrants to continue to expand at its current rate or will its rapid increase level off in the years ahead?

The Field Poll is most interested in addressing these issues in its future surveys. 